\title{
A Case Study of Orthorexia Nervosa: Social Function of a Lifestyle Syndrome
}

\author{
Howard Wilsher S* and Panagiotaki G \\ Norwich Medical School, University of East Anglia, UK \\ *Correspondling author: Howard Wilsher S, Norwich \\ Medical School, University of East Anglia, Norwich \\ Research Park, NR4 7TQ, UK
}

Received: March 01, 2018; Accepted: April 04, 2018; Published: April 20, 2018

\begin{abstract}
We present a longitudinal case study of an 18-year-old man that showed criteria for a diagnosis of orthorexia. Over time, his diet became more compulsively restricted to healthy foods and his partner raised the issue of impaired social function.
\end{abstract}

Keywords: Orthorexia; Eating disorder; Young man; Diet

\section{Introduction}

Orthorexia nervosa was a new eating disorder proposed by Steven Bratman in 1996 [1]. Orthorexia manifests as a rigid eating style motivated by health with possible underlying motivations, such as a need for complete control over health. People with orthorexia limit their food choices to healthy foods and can become obsessive in planning and preparation of meals. Taking strict control of the diet might dominate other activities and impair close relationships.

This new eating disorder does not, as yet, have a clinical diagnosis, although research suggests the pathology of orthorexia overlaps with anorexia nervosa and obsessional compulsive disorder (OCD) and obsessional compulsive personality disorder (OCPD) $[2,3]$. Prevalence of orthorexia is thought to be between $6.9 \%$ in the general population and $58 \%$ in high risk groups such as medical professionals and sports persons [3]. However, measures designed to screen for orthorexia have produced very mixed results and tend to lack reliability and validity [4]. These measures focus on individual factors around food choice and perception of body image, ignoring the social context in which people live. Little qualitative research exists and there has been no assessment about the social context of orthorexia [4].

We present a longitudinal case study of a young man, potentially suffering from orthorexia that was found by chance during research on fruit and vegetable consumption. He presented two criteria for diagnosis proposed by Bratman [5]:

- Compulsive behaviour and/or mental preoccupation regarding affirmative and restrictive dietary practices believed by the individual to promote optimum health.

- Intrapersonal distress or impairment of social, academic or vocational functioning secondary to beliefs or behaviors about healthy diet.

\section{Case Presentation}

A young man aged 18 years participated in research into the drivers and barriers to fruit and vegetable consumption in young men. Jess, his pseudonym, worked full time as a fitness instructor in a small rural market town in Norfolk. The young man lived with his partner who was a nutritionist. The food diary revealed that Jess consumed around six portions of fruit and vegetable per day.
His diet consisted mostly of chicken, fish, pulses, nuts and healthy carbohydrates. The research showed that Jess was health-conscious, with high self-efficacy and control toward his diet and health. He felt that the concept of health included exercise, mental and social health. As a fitness instructor, Jess exercised daily. His mother, a cook, and Jess's partner, Sally, a nutritionist, ensured he consumed plenty of fruit and vegetables. However, there was little in this interview to suggest Jess suffered from orthorexia.

Twelve months later, the research turned toward dyadic relationships about food choice between young men and their meal providers. Jess and his partner Sally were interviewed separately. Jess was the meal provider for himself and Sally who was vegetarian. He took over meal provision when his partner suffered post-natal depression, but Sally prepared all meals for their child. Jess said he was in control of his diet. He planned and prepared his meals for the next day. Jess packed up food to take to work and his diet comprised exclusively of chicken with vegetables or salad, followed by fruit and yoghurt. Sally felt that Jess was fixated on his diet and this caused problems when they dined with friends or relatives. In these circumstances, Jess refused to eat any food that did not fit with his healthy dietary regime and would become anxious. This lead to tension within the relationship and reduced the social function for the couple.

\section{Discussion}

Orthorexia is poorly defined with no clinical diagnosis. However, the young man in this case study presented at least two criteria for diagnosis: compulsive behaviour and impaired social function, which caused anxiety [5].

The early interview did not flag up any psychological issue, however, the food diary showed that the foods consumed were restricted and very healthy. It is possible that between the research time points the young man increased control on his diet to make it "healthier". The longitudinal nature of the research study highlighted this change in behaviour. Another case study showed that a 30 -year old man consumed small amounts of the same foods daily, which lead hospitalization [6]. However, there was no indication about how long this extreme eating behaviour had been followed. Both this and our case study would have scored highly on the ORTO-15 measurement for orthorexia as the target was for healthy eating. Yoga practitioners also have high scores because eating healthily is their
Austin J Nutr Metab - Volume 5 Issue 1 - 2018

Submit your Manuscript | www.austinpublishing group.com

Wilsher et al. (C) All rights are reserved
Citation: Howard Wilsher S and Panagiotaki G. A Case Study of Orthorexia Nervosa: Social Function of a Lifestyle Syndrome. Austin J Nutr Metab. 2018; 5(1): 1056. 
norm [4]. Measurement of healthy eating for people who are engaged in sporting activities appears redundant. Indeed, how exercise and healthy eating are connected requires clarity [4].

Furthermore, interviewing the partner revealed tension within their relationship about social functioning that did not appear in the participants' interview. The participant may not think they have a problem by rigidly controlling their diet, or if they are aware, may try to hide any dissonance in social function. The partner reported that our case became anxious when in a situation where the foods served did not fit his regime. However, anxiety may also have been caused because the food preparation was out of his control as proposed by Bratman [5]. Anxiety in orthorexia differs from anxiety in other eating disorders, such as anorexia nervosa, where it occurs due to worry about appearance and fear of rejection [7]. Social function is an important aspect of orthorexia nervosa, which requires further exploration and its impairment might be a good indicator of this condition.

Qualitative research that includes the social context of orthorexia is much needed to develop our understanding of this condition. Orthorexia is multifaceted, and we risk poor conceptualising of the condition without qualitative exploration to guide the development of quantitative measures.

\section{Conclusion}

Our case study of an 18-year-old man may have highlighted, by chance, how social function can be impaired. It adds evidence that more longitudinal research with the inclusion of social function is much needed to improve our understanding about how orthorexia affects people within their social context.

\section{References}

1. Bratman S. What is orthorexia? 2014.

2. Koven NS, Abry AW. The clinical basis of orthorexia nervosa: emerging perspectives. Neuropsychiatric Disease and Treatment. 2015. 11: 385-394.

3. Varga M, Dukay-Szabó S, Túry F, van Furth EF. Evidence and gaps in the literature on orthorexia nervosa. Eat Weight Disord. 2013; 18: 103-111.

4. Haman L, Natalie Barker-Rucht, Göran Patriksson, Eva-Carin Lindgren. Orthorexia nervosa: An integrative literature review of a lifestyle syndrome. Int J Qual Stud Health Well-being. 2015; 10: 26799.

5. Bratman S. Orthorexia: Proposed formal criteria. 2015.

6. Park SW, Kim JY, Go GJ, Jeon ES, Pyo HJ, Kwon YJ. Orthorexia Nervosa with Hyponatremia, Subcutaneous Emphysema, Pneumomediastimum, Pneumothorax, and Pancytopenia. Electrolytes \& Blood Pressure. 2011; 9: 32-37.

7. Patel K, Tchanturia K, Harrison A. Harrison. An Exploration of Social Functioning in Young People with Eating Disorders: A Qualitative Study. PLoS One. 2016; 11: e0159910.
Austin J Nutr Metab - Volume 5 Issue 1 - 2018

Submit your Manuscript | www.austinpublishing group.com Wilsher et al. (C) All rights are reserved
Citation: Howard Wilsher S and Panagiotaki G. A Case Study of Orthorexia Nervosa: Social Function of a Lifestyle Syndrome. Austin J Nutr Metab. 2018; 5(1): 1056. 